\title{
DERRUBANDO MUROS E CERCAS: NOVAS ABORDAGENS PARA O ENSINO DA GEOGRAFIA NO SÉCULO XXI
}

\section{TEARING DOWN WALLS AND FENCES: NEW APPROACHES TO THE TEACHING OF GEOGRAPHY IN THE 21ST CENTURY}

\author{
MARINO, Leonardo Freire ${ }^{1}$
}

\section{RESUMO}

A escola ocupa um lugar central em nossas vidas. No entanto, desde as últimas décadas do século XX, a escola vive uma crise sem precedentes. Seus objetivos, procedimentos e normas de funcionamento não carregam a eficiência que apresentavam no passado. Parte desta crise tem suas origens na passagem das Sociedades Disciplinares para as Sociedades de Controle e nos processos de construção de novas subjetividades e formas de ser e estar no mundo, aspectos característicos da transição entre os dois modelos de Sociedade. Frente a este cenário, o presente artigo propõe investigar o papel que a Educação Geográfica deve desempenhar nos novos tempos.

Palavras-Chave: Sociedade disciplinar, Sociedade de controle, Ensino de Geografia, Educação Geográfica, Prática de ensino.

\begin{abstract}
The school occupies a central place in our lives. However, since the last decades of the 20th century, the school is living through an unprecedented crisis, its objectives, procedures and standards of operation do not bear the efficiency that had in the past. Part of this crisis has its origins in the passage of the disciplinary societies for the societies of control and in the processes of construction of new subjectivities and ways of being and being in the world, characteristic aspects of the transition between the two models of society. In the face of this scenario, this article proposes to investigate the role that education should Geographic play in new times.
\end{abstract}

KEYWORDS: Disciplinary society, Control society, Geography Teaching, Geographical Education, Teaching practice.

\footnotetext{
${ }^{1}$ Doutor em Geografia (UFF). Professor Adjunto da Universidade do Estado do Rio de Janeiro (UERJ) e Pesquisador do Grupo Geografia Brasileira: História e Política (UERJ). e-mail: leofmarino@gmail.com
} 
DOI: $10.12957 /$ e-mosaicos.2018.33108

\section{INTRODUÇÃO}

Vou começar como faço sempre, dizendo o seguinte: as aulas fáceis não têm o menor interesse; os livros fáceis não têm o menor interesse; as conferências fáceis são uma chantagem em relação aos que se dispuseram a escutá-las. Estou dizendo isto com o temor de que para certos dos presentes algo do que vou dizer possivelmente venha a parecer complicado. Estou desde logo solicitando-lhes a tolerância, mas também a atenção (SANTOS, Milton. 2011).

A escola representa uma tecnologia, um dispositivo, uma ferramenta destinada a atingir objetivos previamente estabelecidos. A escola, a fábrica, 0 hospício e a prisão são instituições criadas em um mesmo período, os séculos XVIII e XIX, e vinculadas a um mesmo modelo de sociedade, caracterizado por diversos autores, entre eles Foucault (2008 e 1987) e Deleuze (1992), pelo sugestivo nome de Sociedade Disciplinar. De forma simplificada, podemos conceituar a Sociedade Disciplinar como o estabelecimento de mecanismos de controle social por meio do ingresso dos indivíduos em espaços de confinamento. Nas Sociedades Disciplinares, o corpo era encarado como a matéria-prima a ser moldada em uma máquina e a vida se tornava, consequentemente, objeto dos mecanismos de sujeição as estruturas de poder vigentes.

A plataforma que ergueu a escola, assim como, as demais instituições, ostentava um lema claro, a disciplinarização dos indivíduos e, consequentemente, das massas. Em seu funcionamento as instituições disciplinares buscava mordenar os indivíduos, estabelecendo uma distinção entre o normal e o patológico, entre o aceitável e o inaceitável, convertendo o homem em um indivíduo ordeiro, submetido as normas de convívio social e econômico. Neste cenário, a escola não representava apenas um espaço destinado a transmissão de conhecimentos, mas, principalmente, um espaço destinado ao adestramento dos indivíduos; a aceitação tácita do sistema de leis e normas vigentes. O que garantiria o pleno funcionamento das instituições disciplinares, a excelência dos processos econômicos e o bem-estar social. Aspectos que configurariam o que Foucault (1987) retratou como a produção de 'Corpos Dóceis ${ }^{2}$.

\footnotetext{
2 "O momento histórico das disciplinas é o momento em que nasce uma arte do corpo humano, que visa não unicamente o aumento de suas habilidades, nem tampouco aprofundar sua sujeição, mas a formação de uma relação que no mesmo mecanismo o torna mais obediente quanto e mais útil, e inversamente. (...) A disciplina fábrica assim corpos submissos e exercitados, corpos 'dóceis'. A disciplina aumenta as forças do corpo (em termos econômicos de utilidade) e diminui essas mesmas forças (em termos políticos de obediência). Em uma palavra: ela dissocia o poder do corpo; faz dele por um lado uma 'aptidão', uma 'capacidade' que ela procura aumentar; e inverte por outro lado a energia, a potência que poderia resultar disso, e faz dela uma relação de sujeição estrita" (FOUCAULT, 1987, p. 119).
} 


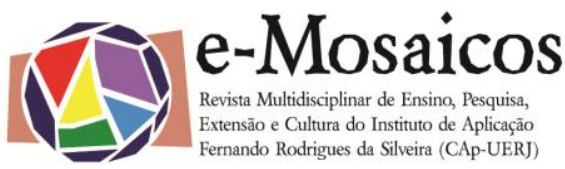

DOI: $10.12957 /$ e-mosaicos.2018.33108

Frente a tais objetivos, foi constituído o hábito de enviarmos nossas crianças, desde muito pequenas, para as instituições escolares. Tal hábito foi estabelecido com a intenção de garantir o condicionamento dos indivíduos, habituando-os a permanecerem tranquilos, a cumprirem prontamente o que lhes for ordenado e a não questionar as hierarquias socialmente impostas. De acordo com esta perspectiva, não adentrar o pátio escolar implica um grave problema, uma vez que indica a existência de um indivíduo que não foi conformado, o que poderá acarretar, o surgimento de um sujeito indisciplinado, não cumpridor das normas, um potencial transgressor das leis, um marginal, no sentido daquele que vivemà margem da sociedade. De maneira análoga, o mesmo procedimento classificatório envolve os indivíduos que não conseguem permanecer no ambiente escolar, indivíduos que por apresentarem comportamentos considerados inadequados aos estabelecidos pelos mecanismos disciplinares, são expurgados dos espaços escolares ${ }^{3}$.

Simultaneamente à disciplinarização dos indivíduos ocorreu uma uniformização cultural. No interior das escolas, apoiados em normas de conduta e em procedimentos formativos, as diversas manifestações culturais que não se enquadravam na visão hegemônica, foram, gradualmente, desqualificadas e abandonadas. A imposição de símbolos pátrios, tais como línguas, bandeiras e hinos, representam exemplos expressivos deste processo. Foi com a força da coação disciplinar imposta nas salas de aula por professores, que as identidades nacionais foram construídas e milhares de dialetos utilizados nos tempos pré-modernos foram abandonados e desapareceram. Assim, ler e escrever, princípios basilares do modelo escolar, não podem ser considerados como valores universais e atemporais, não são marcas da vida humana, pelo contrário, representam exemplos do processo de escolarização viabilizado na Sociedade Disciplinar.

Ao longo do século $\mathrm{XX}$, a escola alcançou uma maior centralidade entre as instituições disciplinares, constituindo uma instância formativa capaz de dar sentido a existência das demais instituições. Na megamáquina escola, as moldagens determinavam o abandono das individualidades, as singularidades dos sujeitos, seus desejos e sentimentos constituíam aspectos que deveriam ser enfrentados, disciplinados, servindo, em muitos momentos, como motivo de punições e sanções ${ }^{4}$.

A escola, como concebida, representa uma instituição alicerçada em um modo peculiar de ser e estar no mundo, uma instituição que se ocupou em conformar os

\footnotetext{
3 "O discurso dominante traz ao primeiro plano uma concepção de escola como instituição salvadora, cuja missão impossível é tirar das ruas crianças e jovens moradores nas áreas urbanas mais precárias das cidades e assim diminuir os índices de criminalidade, seja ensinando-lhes princípios de moral e bons costumes seja fornecendo-Ihes um diploma ilusório que não Ihes garantirá emprego em tempos de desemprego estrutural" (PATTO, 2007, p. 244).

4 "(...) o indivíduo não cessa de passar de um espaço fechado a outro, cada um com suas leis: primeiro a família, depois a escola ("você não está mais na sua família"), depois a caserna ("você não está mais na escola"), depois a fábrica, de vez em quando o hospital, eventualmente a prisão, que é o meio de confinamento por excelência" (DELEUZE, 1992, p. 219).
} 
indivíduos aos padrões de conduta e as normas socialmente estabelecidas. Porém, em nossos dias, a escola perdeu parte de sua funcionalidade, sofrendo críticas constantes e fortes contestações sobre sua eficiência. Tal crítica se alicerça em profundas mudanças sociais. Vivenciamos uma transição entre modos de ser e estar no mundo, entre modos de vida que eram mais compatíveis com o modelo escolar tradicional, que se adaptavam mais facilmente as diversas tecnologias disciplinares, e modos de vida que não se adequam mais a um ambiente de confinamento, que carregam imensas dificuldades para se encaixarem nas moldagens disciplinares, que manifestam uma fragrante desconformidade com as instituições escolares.

A perda de eficácia no funcionamento das estruturas escolares indica uma crise que envolveria todas as estruturas criadas neste período. Nas palavras de Deleuze (1992, p. 220), "encontramo-nos numa crise generalizada de todos os meios de confinamento, prisão, hospital, fábrica, escola, família". O resultado da crise do modelo escolar se manifesta na multiplicação de conflitos e na ampliação de alunos e professores infelizes com suas práticas cotidianas. A contestação de seu funcionamento não representa o seu abandono. Mas, a necessidade de uma reflexão profunda de seus métodos e procedimentos.

A escola, como concebida e perpetuada ao longo dos últimos séculos, não se tornou obsoleta, mas, atualmente, constitui uma máquina antiquada, pouco eficiente e com reduzida produtividade. $O$ aparato escolar, predominante em nossos dias, não carrega conexões com os jovens do século XXI $\mathrm{XI}^{5}$. Convivemos com uma divergência de época, um desajuste coletivo entre o modelo de escolarização predominante e seus alunos. As tensões não são exclusivas do ambiente escolar. No entanto, a escola continua ocupando um lugar de destaque na sociedade, apresentando um elevado prestígio social, o que decorre, sobretudo, do seu potencial transformador.

\section{RUPTURAS E PERMANÊNCIAS NO APARELHO ESCOLAR}

A contestação das instituições criadas nas Sociedades Disciplinares levou Deleuze (1992) a apontar para o surgimento do que ele nomeou pelo sugestivo nome de Sociedade de Controle. Para Deleuze, as antigas estruturas de confinamento perderam importância, uma vez que, em nossos dias, os processos de sujeição dos indivíduos se dispersaram no tecido social e se desprenderam das instituições, tornando seus muros, seus limites, obsoletos. Na Sociedade de Controle as lógicas disciplinares se espraiaram pelo tecido socioespacial. O espraiamento dos mecanismos de sujeição, não representa a perda de eficácia ou de potência dos mecanismos de imposição das disciplinas, mas, a sua generalização, uma vez que eles assumiram uma forma fluida, dispersa e totalizadora. O controle, neste sentido,

\footnotetext{
5 "Trata-se, em suma, de organismos que não se ajustam tão harmoniosamente quanto costumava suceder algum tempo atrás, e que, por conseguinte, ao serem postos em contato, tendem a desencadear conflitos de toda espécie da mais variada gravidade" (SIBILIA, 2002, p. 13).
} 


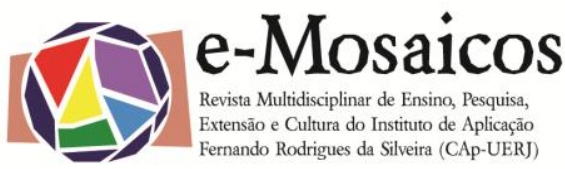

DOI: $10.12957 /$ e-mosaicos.2018.33108

constitui uma intensificação e uma generalização dos mecanismos disciplinares, uma vez que as fronteiras institucionais se tornaram permeáveis. Neste cenário, as antigas noções de interno e externo, de intramuros e extramuros, de privado e público, de próximo e distante, fundamentais para o funcionamento das instituições construídas pelo modelo disciplinar, perderam sentido ${ }^{6}$.

Para Deleuze (1992), a explicação para o soerguimento da Sociedade de Controle residiria nas transformações que ocorreram no sistema capitalista. 0 capitalismo do século XIX apresentava uma forte concentração espacial, nele a fábrica concebia não apenas um espaço produtivo, mas, uma insígnia, um arquétipo, do modelo social vigente ${ }^{7}$. Em nossos dias, a economia não é mais dirigida pela produção, mas, pelos fluxos, pelas redes produtivas e, sobretudo, pelo sistema financeiro:; vivemos em um sistema voltado para o mercado e assentado nos serviços; características que tornaram as dinâmicas de acumulação fluídas, espraiadas e móveis.

$\mathrm{Na}$ Sociedade Disciplinar os indivíduos eram submetidos a permanências temporais, a confinamentos que se sucediam ao longo dos dias, dos meses, dos anos e que produziam instantes de condicionamento ao longo da vida. O objetivo era garantir que as normas fossem internalizadas, criando um modo de ser e estar no mundo próprio de seu tempo. Atualmente, na Sociedade de Controle, a formação torna-se permanente, o que produz um abandono dos instantes de sujeição, uma vez que o controle passa a fazer parte do ser e se encontra disperso por todo o tecido socioespacial. Os controles constituem uma modulação, uma moldagem adaptável, imanente aos indivíduos e condicionante dos sujeitos.

Em uma sociedade fortemente midiatizada, fascinada pelo efêmero e pela visibilidade, as moldagens que habitavam os indivíduos entraram em colapso. Nos novos tempos, o confinamento que era determinante para a introjeção das normas, foi profundamente alterado pelo uso de novas tecnologias. Os dispositivos eletrônicos e digitais com que convivemos e utilizamos, cotidianamente, tem provocado o surgimento de novas estruturas de sujeição.Vivemos em um sistema apoiado pelo marketing virtual e pela publicidade exposta de maneira velada, pela

\footnotetext{
${ }^{6}$ Neste ponto uma ressalva deve ser feita, pois a passagem de um modelo social para outro não constitui uma gradação de um menos eficiente para um mais eficiente instrumento de controle e subordinação social. De acordo com Deleuze "não se deve perguntar qual regime é o mais duro, ou o mais tolerável, pois é em cada um deles que se enfrentam as liberações e as sujeições" (DELEUZE, 1992, p. 220).

${ }^{7}$ DELEUZE, 1992, pp. 220-221.

8 "O próximo e o distante ligam-se quase que instantaneamente pela mediação da mídia; mas não só dela pois não podemos esquecer da tendência à flexibilização do trabalho que faz emergir um novo personagem que é o ciber-executivo que passa a maior parte do tempo fora da empresa, mas a ela conectado pela comunicação móvel baseada na telefonia celular nos micros computadores portáteis. A isso se associa a ideia do telecommutinge a internet, onde uma gama cada vez mais diversificada e densa de serviços online são oferecidos mudando o modo como se realiza o trabalho no mundo moderno" (CARLOS, 2007, p. 24).
} 


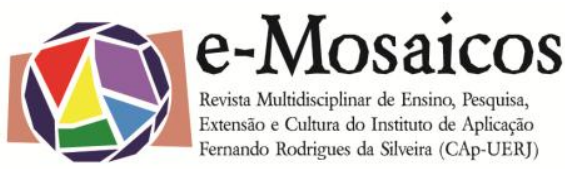

DOI: $10.12957 /$ e-mosaicos.2018.33108

imposição do consumo ancorado em mecanismos de normatizaçãode costumes por meio das redes informacionais ${ }^{9}$.Nos novos tempos, é comum que determinados hábitos, quando compartilhados virtualmente, passem a ser adotados por indivíduos espacialmente distantes e socialmente afastados.

Os jovens adotam o novo de forma visceral e naturalizada, enquanto que as gerações pretéritas não carregam a mesma capacidade. O resultado do descompasso não envolve apenas o aspecto tecnológico, mas, um enfrentamento geracional, pois muitos dos novos hábitos não são compreendidos pelas gerações mais velhas. 0 choque de gerações, por sua vez, não resulta de uma pura e simples resistência ao novo, ele é produto da coexistência de indivíduos condicionados em estruturas de sujeição distintas. Vivemos um cenário marcadamente heterogêneo, caracterizado pela existência de um pluralismo normativo, com indivíduos oriundos de processos condicionantes distintos. Portanto, os conflitos que emergem do desencaixe geracional, constituiria uma marca transitória do presente ${ }^{10}$.

De acordo com Deleuze (1992) as sociedades podem ser caracterizadas por determinados tipos de máquinas, uma vez que tais artefatos exprimem as formas sociais que thes deram nascimento e que são capazes de as utilizarem ${ }^{11}$.Os equipamentos eletrônicos constituem as marcas do nosso tempo, especialmente, no que diz respeito ao tempo de existência dos indivíduos mais jovens. Não por outra razão, é sobre a utilização de equipamentos eletrônicos nos ambientes escolares que residem alguns dos mais significativos conflitos registrados. Diariamente, obrigamos nossos jovens e crianças, indivíduos que nasceram em ambientes fortemente influenciados pelas novas tecnologias e pela existência de redes informacionais, a se submeterem aos arcaicos, envelhecidos e enferrujados procedimentos disciplinares, ainda extremamente presentes no ambiente escolar.

Para a infelicidade de nossos jovens, nossas escolas funcionam assentadas em estruturas e procedimentos criados há vários séculos e, com raras exceções, as

\footnotetext{
${ }^{9}$ LIPOVETSKY, 2015.

10"Houve no passado, sem dúvida, diversos tipos de antagonismos culturais. Mas estes opunham ou religiões entre si (conflitos inter-religiosos), ou, mais tarde, os princípios modernos à ordem tradicional persistente (a laicidade contra o domínio institucional da religião, a liberdade individualista dos modernos contra as imposições coletivas tradicionais, os movimentos progressistas contra os adversários da modernização, a arte moderna contra o academismo). Não é mais assim em nossos dias, ainda que todas as formas de conflitos comunitários e inter-religiosos estejam longe de haver desaparecido. Inúmeros antagonismos culturais de que somos testemunhas não põem mais frente a frente valores herdados de sistemas radicalmente antinômicos (modernidade contra tradição): ao contrário, eles são plenamente intramodernos"(LIPOVETSKY, 2015, p. 277).

${ }^{11 " A s ~ a n t i g a s ~ s o c i e d a d e s ~ d e ~ s o b e r a n i a ~ m a n e j a v a m ~ m a ́ q u i n a s ~ s i m p l e s, ~ a l a v a n c a s, ~ r o l d a n a s, ~ r e l o ́ g i o s ; ~}$ mas as sociedades disciplinares recentes tinham por equipamento máquinas energéticas, com o perigo passivo da entropia e o perigo ativo da sabotagem; as sociedades de controle operam por máquinas de uma terceira espécie, máquinas de informática e computadores, cujo perigo passivo é a interferência, e o ativo a pirataria e a introdução de vírus" (DELEUZE, 1992, p. 222).
} 
novas tecnologias não são incorporadas em sua plenitude ao ambiente escolar ${ }^{12}$. 0 mundo mudou, os jovens mudaram, as tecnologias evoluíram, no entanto, continuamos operando em nossas escolas com procedimentos criados em realidades pretéritas. No mundo interconectado no qual vivemos, nossa relação com os saberes mudou. A internet e as conexões produzidas pelas redes sociais tornaram o acesso ao conhecimento muito mais democrático do que foi no passado. Guardada as devidas limitações provocadas pela desigualdade de acesso as novas redes e tecnologias, atualmente, cada indivíduo, dotado de um equipamento eletrônico, como por exemplo, um smartphone, sem realizar qualquer deslocamento físico, pode participar dos debates que inflamam nossa sociedade, conectar-se com fóruns de discussões que envolvem indivíduos de todo o globo terrestre e produzir conhecimentos e conteúdos variados; uma nova forma de espaço público nasceu e nele a praça física perdeu a função de espaço exclusivo de luta, passando a conviver harmoniosamente com a praça virtual.

O papel da escola deve ser transformado, devemos derrubar seus muros e cercas, substituí-los por redes, por conexões; devemos abandonar sua função de sujeição, de disciplinarização; devemos transformar as escolas em espaços de autonomização, de construção de novas competências, de fomento da criatividade, de posicionamento crítico aos acontecimentos socioespaciais e, sobretudo, de resistência aos processos alienantes que as novas dinâmicas produzem ${ }^{13}$. Contudo, se a escola permanece relevante, o mesmo não pode ser afirmado de seus procedimentos, que precisam ser revistos. É preciso adaptar a escola, suas práticas e seus saberes aos novos tempos, as novas subjetividades, garantir que ela consiga desempenhar novas funções, se afastando dos processos de disciplinarização que muitas instituições persistem em exercer.

Frente ao cenário exposto, é fundamental indicarmos possíveis caminhos para serem trilhados, o que representa um grande desafio, posto que vivemos um período de transição, um período em que o novo ainda não se consolidou e o antigo ainda se faz presente. Contudo, frente às necessidades imperativas da crise, apontar uma trilha plausível de ser percorrida é imprescindível. Sobre esse prisma, a seguir discutiremos o papel da educação geográfica neste novo cenário. Buscaremos

\footnotetext{
12"alimentam as engrenagens oxidadas dessa instituição de confinamento fundada há vários séculos e que, mais ou menos fiel a suas tradições, continua a funcionar com o instrumental analógico do giz edo quadro-negro, dos regulamentos e boletins, dos horários fixos e das carteiras alinhadas, dos uniformes, da prova escrita e da lição oral" (SIBILIA, 2012, p. 52).

13 "O ensino fundamental e o médio devem ser, acima de tudo, desafiadores, capazes de despertar o interesse dos alunos para a resolução dos problemas que a via apresenta. Hoje, na chamada pósmodernidades, a escola deve proporcionar os caminhos necessários para que os sujeitos/alunos possam compreender o cotidiano, desenvolvendo e aplicando competências. Para que essa mudança ocorra, os professores e a instituição da escola, na sua complexidade, devem estar comprometidos com o que chamamos de 'fazer sociedade com cidadania'. A escola deve provocar o educando para conhecer e conquistar o seu lugar no mundo em uma teia de justiça social" (CASTROGIOVANNI, 2007, p. 44).
} 
DOI: $10.12957 /$ e-mosaicos.2018.33108

responder a um questionamento basilar: será a Geografia escolar uma disciplina necessária aos novos tempos ou a mesma deve ser abandonada?

\section{A EDUCAÇÃO GEOGRÁFICA FRENTE AOS NOVOS TEMPOS}

Os geógrafos são insuportáveis! Eles falam de sua disciplina como de uma ciência, quando ela é um saber banal, ao alcance de todo mundo! (...) Ela se exprime na língua de todos os dias, se mostra em imagens diretamente compreensíveis. Não é um saber elaborado, baseado em abordagens sofisticadas (CLAVAL, 2010, p. 9).

Antes de se configurar como um saber científico, complexo e diversificado em metodologias, a Geografia produz discursos, estrutura habilidades e gera conhecimentos empíricos que todos os indivíduos, conscientemente ou não, utilizam diariamente. Tal aspecto faz com que a Geografia carregue em seu âmago uma vitalidade, uma utilização prática e uma história anterior ao surgimento das Ciências Modernas. Claval (2010), na passagem em epígrafe, apoiado em tais características, aponta que a Geografia constitui um saber banal, um saber simplificado atrelado à vida humana.

Apesar de sua simplicidade prática e sua longa história, a Geografia, como uma Ciência Moderna, carrega uma história recente, ligando-se aos processos de consolidação do sistema capitalista e de formação dos Estados Nacionais. Ao passo que 0 capitalismo se consolidava, expandindo sua área de atuação e, consequentemente, integrando diversos grupos humanos ao modo de vida europeu, surgiu a necessidade de sistematização dos conhecimentos geográficos. Porém, contrariando um processo comum a outros ramos do conhecimento humano, a Geografia não se consolidou entre as Ciências Modernas para, posteriormente, atingir as salas de aula; pelo contrário, foram a sua presença entre as cátedras escolares e, fundamentalmente, a necessidade de formação de professores, as razões que levaram a formação dos Cursos Universitários de Geografia ${ }^{14}$.Foi a necessidade de formar professores capazes de lecionar a Geografia nas escolas, a responsável pela constituição da Geografia como uma cadeira acadêmica reconhecida e importante ${ }^{15}$.

\footnotetext{
${ }^{14} \mathrm{~A}$ antecedência do saber geográfico nas salas de aula tem sua origem associada aos processos de construção das identidades nacionais, pois assim como as línguas e os símbolos pátrios, as descrições produzidas pela geografia representam marcas das identidades nacionais.

15 "La geografia, sin embargo, no se institucionalizó em la Universidad por la acción de estas Sociedades. La creación de cátedras de esta disciplina em los centros universitários se hizo intensa a partir de 1860 y, en general, tiene que ver com las necessidades de la enseñanza. La presencia invariable de la geografia em los programas de enseñanza básica cuando estos se fueron fijando durante el siglo XIX obligó a formar profesores de geografia, locual, a sua vez, impulso la creación de cátedras universitárias" (CAPEL, 1983, p. 18).
} 
DOI: $10.12957 /$ e-mosaicos.2018.33108

A longa e forte presença da Geografia nas salas de aula evidencia seu papel na construção e consolidação dos processos disciplinares. Por meio de um regente de Geografia foram construídas as bases de muitos aspectos necessários a formação das identidades nacionais, especialmente, associadas as suas características naturais e humanas, conhecimentos fundamentais para a consolidação do sistema de Estados Modernos $^{16}$. Neste sentido, em seus primeiros momentos, a Geografia escolar se pautou pela diferenciação das paisagens (naturais e humanas) e pela construção dos conjuntos regionais. Seus procedimentos didáticos, apoiados quase que exclusivamente na descrição e na memorização, foram fundamentais para a efetivação dos sentimentos de pertencimento as nações.

Ao longo do século $\mathrm{XX}$, as bases do conhecimento geográfico passaram por diversas transformações. Neste percurso, surgiram novas correntes de pensamento e, desde meados dos anos 1990, convivemos com o que podemos caracterizar como uma Geografia escolar 'híbridd. O hibridismo na Geografia escolar demonstra o processo de evolução do pensamento geográfico, aspecto positivo e marcadamente presente em todos os ramos das Ciências Modernas. A coexistência de conceitos e categorias oriundos de matrizes de pensamento distintas indica a existência de uma Geografia escolar viva e rica. No entanto, a permanência de métodos e procedimentos pensados e propostos nos primórdios de sua formação como disciplina escolar, aponta para um caminho inverso, a persistência de uma Geografia escolar morta e pobre.

O hibridismo conceitual não representa um entrave para práticas escolares ricas e significativas. Pelo contrário, a multiplicidade conceitual favorece a diversidade de discussões, os quadros analíticos variados e a pluralidade de enfoques. Contudo, o docente deve ter clareza sobre o caminho a ser percorrido e que opções devem ser realizadas ao longo dos percursos pedagógicos, optando conscientemente e coerentemente por metodologias que não confundam, mas esclareçam seus objetivos. Infelizmente, o descompasso entre o que se busca e o como se atinge o objetivo proposto, tem levado muitos docentes a adotarem procedimentos metodológicos que, em alguns casos, podem ser considerados antagônicos e anacrônicos.

\footnotetext{
16"A geografia, como um campo do conhecimento científico, apresenta, ao longo de sua história, uma visão ocidental eurocêntrica de conceber o mundo, ou seja, uma forma de avaliar os lugares que se fundamentou em dois processos simultâneos: a expansão colonial, um processo de espalhamento da Europa por toda a superfície da Terra, e o processo de afirmação das identidades estatais nesse próprio continente. A geografia se colocou como um instrumento, talvez como o próprio elemento de ligação entre esses dois movimentos (e hoje em dia sabemos bem que não haveria modernidade sem colonialidade). Em suma, a geografia legitimou com um peso muito grande o nexo entre a expansão colonial europeia e a formação dos Estados modernos na Europa" (MORAES, 2013, p. 7).
} 
DOI: $10.12957 /$ e-mosaicos.2018.33108

A confusão metodológica tem contribuído para gerar uma Geografia escolar ambígua, tediosa e desinteressante ${ }^{17}$.Tal fato não se associa apenas ao descompasso entre o quadro conceitual e as metodologias utilizadas. Vivemos uma transição entre modelos sociais e o desencaixe crescente entre os jovens e as escolas provoca questionamentos a respeito da validade do que se estuda e do que, realmente, deveria ser ensinado. Tal aspecto é natural e esperado, as mudanças de paradigmas são sempre acompanhas de conflitos, tensões e desafios. Infelizmente, muitos professores ainda carregam as marcas de um modelo escolar tradicional, de um sistema marcado pela obediência tácita e irrestrita aos seus ditames; de um saber rígido, oriundo de manuais e descolado da realidade. No extremo oposto, nossos jovens exigem cada vez mais práticas flexíveis, abertas ao novo, mais democráticas e assentadas em saberes que carregam significado. Este descompasso tem provocado o afastamento do fazer geográfico nas escolas e contribuído para o estabelecimento de uma Geografia escolar desinteressante, cansativa e, em alguns momentos, incapaz de dialogar com os jovens.

O crescente desinteresse pelo conhecimento geográfico nas escolas não significa que a educação geográfica se tornou obsoleta. A Geografia escolar, assim como a própria escola, continua carregando um valor social fundamental. Fato que decorre, especialmente, de suas intrínsecas relações com o mundo vivido, com os saberes populares (banais) e com a capacidade de autonomizar os jovens para a compreensão do sistema-mundo ${ }^{18}$. No entanto, se sua importância como um conhecimento escolar permanece, seus procedimentos metodológicos precisam ser revistos. As mudanças são inevitáveis e as práticas tradicionais se transformaram em barreiras para a autonomização dos alunos.

Seguindo este caminho, a seguir apontaremos alguns princípios que consideramos como fundamentais para a construção de uma nova educação geográfica. Vale ressaltar que não pretendemos construir um receituário de como a Geografia escolar deve ser construída, não existe a pretensão de guiar

17 "A ruptura da cultura escolar, que, ainda hoje, está sobreposta no currículo, com temas enfadonhos, parece ser um dos grandes desafios da escola. A compartimentação do saber cria insegurança e insatisfação no saber para saber fazer melhor. $O$ aluno não adquire confiança nas propostas da escola e acha que não aprendeu nada e, mesmo que tenha aprendido, não sabe onde nem como utilizar. Acontece, assim, uma exclusão interna da escola" (CASTROGIOVANNI, 2007, p. 44).

${ }^{18}$ A Geografia carrega um papel formativo que deve "ajudar as pessoas a entenderem o mundo em que vivem. Essa é a meta, ao mesmo tempo simples e ambiciosa, profunda e específica: ajudar as pessoas a se localizarem. Mais do que a simples localização geodésica, poder-se-ia dizer que a meta básica da geografia é oferecer às pessoas conhecimentos que lhes permitam entender os lugares onde estão inseridas. Tendo como tema, por excelência, a relação entre os grupos humanos e a superfície terrestre, a questão posta a esta ciência é como se dá a instalação das sociedades nos diferentes lugares: a apropriação desses lugares, a transformação desses lugares, a organização política e econômica desses lugares. O que dá o tom da busca teórica da geografia é, portanto, a ocupação humana da Terra" (MORAES, 2013. p. 2). 
DOI: $10.12957 / \mathrm{e}-m o s a i c o s .2018 .33108$

metodologicamente as práticas docentes, mas, apenas, relacionar alguns aspectos procedimentais e atitudinais que consideramos relevantes para a construção de uma Geografia escolar adaptada aos novos tempos.

\section{Precisamos fugir de UM SABER geOgRÁfico PARCELADO}

O pensamento científico moderno se estruturou por meio da separação de campos de conhecimento. Tal fato resultou em um sistema marcado pela especialização acadêmica, pela construção de um saber parcelado e pela construção de disciplinas desarticuladas. Apoiado no parcelamento, o conhecimento cientifico moderno quantificou e desintegrou a realidade em fragmentos e estabeleceu análises pormenorizadas, nas quais a realidade foi anulada e a diversidade, a multiplicidade e a desordem dos fenômenos foram decodificada em modelos analíticos engessados.

A divisão do saber em compartimentos foi aprofundada com a consolidação do processo de industrialização, sobretudo, pelas necessidades econômicas na formação de profissionais responsáveis por determinadas atividades. As moldagens escolares serviram a este propósito, e o parcelamento do conhecimento levou a construção de um cenário marcado por disciplinas isoladas, em que cada uma delas se especializou em analisar as diversas facetas da vida de maneira disjunta. Com base nas estruturas de pensamento moderno, construímos uma compreensão da realidade em partes, em porções simplificadas.

A consequência destas práticas no ambiente escolar foi a formação de jovens que apresentam dificuldades em construir conhecimentos globais, integrados e capazes de abarcar a complexidade da vida humana. Ao fragmentarmos a realidade em disciplinas e saberes escolares isolados, afastamos nossos pensamentos da complexidade da vida e não contribuímos para a compreensão do mundo em suas múltiplas dimensões.

Em relação à Geografia, o parcelamento dos saberes produziu um paradoxo, uma vez que a ciência do espaço do homem procura integrar em suas análises os elementos humanos e naturais ${ }^{19}$.A Geografia carrega um discurso unitário em torno do espaço, no entanto, seu método de análise é dual, uma vez que em seus estudos, procura-se analisar a natureza, empregando métodos das ciências naturais, e a sociedade, por intermédio de métodos das ciências humanas. Assim, a compartimentação dos saberes, comum as ciências modernas e presente na estruturação das disciplinas escolares, não produziu na Geografia, uma identidade cientifica limitadora. Pelo fato de envolver em suas discussões uma compreensão integradora da natureza e da sociedade, os geógrafos foram levados a construir uma

${ }^{19}$ SANTOS, Milton. 2007: 29. 
estrutura de pensamento transdisciplinar e que tende a complexificar suas análises da realidade ${ }^{20}$.

Apesar da natureza transdisciplinar da Geografia, a educação geográfica temse pautado por um saber compartimentado, fragmentado e pouco articulado. Em diversos momentos, os temas e as estruturas de análises abordadas na Geografia escolar ocorrem em um arcabouço metodológico que dissocia os aspectos naturais dos sociais e, sobretudo, não conseguem levar a compreensão do espaço geográfico em sua totalidade.

O espaço geográfico é formado por um conjunto indissociável, solidário e também contraditório, de sistemas de objetos e sistemas de ações, não considerados isoladamente, mas como um quadro único no qual a história humana transcorre ${ }^{21}$. 0 estabelecimento de uma espacialidade parcelada, que dissocia os objetos (materialidade) das ações (sociedade) não contribui para a construção de uma educação geográfica efetiva. Neste sentido, para que o Ensino daGeografia produza uma compreensão espacial adequada aos novos tempos, devemos abandonar as caixas de conteúdos presentes no Ensino, especialmente, no que tange as Geografias (urbana, agrária, física, econômica entre outras) e em seu lugar estabelecer uma discussão que trate do espaço em sua integralidade e que construa uma Geografia única.

Santos (2011), de forma elucidativa, indica um caminho que pode ser trilhado na educação geográfica. Para ele, devemos abandonar as parcialidades, os fragmentos do espaço, e estabelecer análises que se fundamentem no que ele nomeou de espaço banal. O espaço banal representaria o espaço de todos os homens, nele os indivíduos, independentemente de sua posição social, participam de sua construção; o espaço banal constituiria o lugar do acontecer solidário, não o espaço especializado, particular, adjetivado, fragmentado e parcelado, é nele que a interdependência se realiza, o que é provocado pelas situações de contato e de convivência ${ }^{22}$. É sobre esse prisma, apoiado na complexidade e na diversidade, inerentes ao espaço apropriado pela vida humana, que devemos focar nossas

\footnotetext{
20 "A Geografia em um contexto em que se classifica e se prática uma ciência disjunta, individualizada através de objetos que devem ser diferentes e únicos a cada ciência, se propõe em constituir uma ciência da relação entre natureza e sociedade, uma ciência da conjunção do natural e do social" (SUERTEGARAY, 2003, p. 44).

${ }^{21}$ SANTOS, Milton. 2002:63.

22 "As diversas geografias, isto é, a geografia dos transportes, a geográfica do comércio, a geografia da população, a geografia da indústria, etc... são parcialidades que levam em conta aspectos isolados do acontecer, às vezes como se fosse possível, além de isolar para a análise, fazê-lo, também, para síntese, o que é um grande risco. Estas espacializações singulares, como os transportes que fluem numa área, ou como o comércio, alteram o significado de uma região. Não é o espaço que se estuda assim, mas sim fragmentos dele. Quando me refiro à realização da economia, da sociedade, da cultura, da política, o que eu tenho são espaços adjetivados, o espaço econômico, o espaço cultural, o espaço político, o espaço social, mas o que quero entender e preciso entender, é o espaço banal". SANTOS, Milton. 2011, p. 9.
} 
práticas em sala de aula. Precisamos nos afastar das 'diversas geografias', dos retículos analíticos, presentes em inúmeros currículos escolares, para em seu lugar construir uma Geografia que se paute pela integralidade, pela conectividade e pela interdependência dos elementos espaciais; uma Geografia que pense a um só tempo os objetos (a materialidade) e as ações (a sociedade) e que tenha na vida humana seu foco.

Em um sentido mais amplo, buscando construir uma aprendizagem mais significativa, precisamos introduzir em nossas escolas abordagens que encarem a realidade de maneira integrada, que enfrentem a complexidade do mundo e que sejam capazes de reduzir o distanciamento estre os saberes ${ }^{23}$. Com base nesta perspectiva, as diferentes interfaces da realidade, abordadas nas distintas disciplinas, não devem ser pensadas ou propostas em separado, elas devem ser pensadas em uma teia de conhecimentos, em uma visão complexa da realidade, pois os saberes parcelares, restritos pelos limites disciplinares, raramente, contribuem para a compreensão das informações em seu contexto. Neste processo, os percursos pedagógicos não devem ser construídos por meio de disciplinas isoladas, eles devem se pautar em temas transversais, ou seja, as especificidades disciplinares devem estar vinculadas a conteúdos próximos e integrarem um quadro temático próprio. Tal fato aponta para uma profunda reconstrução dos currículos escolares, que, para se adequarem aos novos tempos, devem estar pautados em temas correlatos a todas as disciplinas, preservando seus aspectos específicos, porém, vinculando-os a objetivos comuns.

\section{Precisamos AdOtAR UMA ABORDAgem MULTIESCALAR}

A Geografia apresenta em suas análises a capacidade de articular diferentes escalas em torno de seus conteúdos e objetos de estudo. Contudo, no que tange a Geografia escolar, consolidou-se uma visão de que o lugar deve pautar o saber trabalhado em sala de aula, servindo como o ponto de partida preferencial para diversas abordagens geográficas. A supremacia do lugar frente às demais escalas de análise é uma consequência direta das teorias propostas por Piaget (1976). Para Piaget, os sujeitos em seus processos de aprendizagem operam com duas perspectivas de abstração, a empírica e a reflexiva.

A abstração empírica envolve a capacidade de os sujeitos refletirem sobre os objetos que estão em contato direto. Desta forma, o espaço vivido, o lugar, serviria de base para os processos de aprendizagem apoiados na abstração empírica, ou

\footnotetext{
${ }^{23}$ O termo Aprendizagem Significativa apoia-se nos pressupostos formulado pelo pensador norteamericano David Ausubel. Para ele o processo ideal de aprendizagem ocorre quando uma nova ideia se relaciona aos conhecimentos prévios do indivíduo. Motivado por uma situação que faça sentido, proposta pelo professor, o aluno amplia, avalia, atualiza e reconfigura a informação anterior, transformando-a em saber.
} 
seja, a realização de análises por intermédio do contato direto com o objeto estudado. A abstração reflexiva operaria em um nível de raciocínio mais complexo, emanando da comparação, da diferenciação, da associação e as aplicações conceituais frente a situações que envolveriam diferentes escalas de análise. Nela o próximo e o distante devem ser colocados em permanente relação, ou seja, na abstração reflexiva o processo de aprendizagem não derivaria apenas do vivido, do manipulado, do tocado e do observado, mas, fundamentalmente, do conhecido.

Em nossos dias, frente aos aparatos informacionais e o soerguimento da Sociedade de Controle, os indivíduos são submetidos a uma constante e maciça exposição de informações. Neste cenário, o longínquo se materializou como um objeto conhecido. As novas redes de comunicação e transporte permitiram a ampliação do conhecimento sobre o globo terrestre, integrando ao local informações emanadas de pontos distantes do planeta. Assim, o lugar, que manifestaria a instância, por excelência, da abstração empírica, passou a revelar aspectos que permitem, igualmente, o estabelecimento de abstrações reflexivas.

Ao encararmos o lugar como espaço de abstrações empíricas e reflexivas, necessitamos estabelecer uma prática de ensino que estabeleça análises pautadas pela multiescalaridade. Atualmente, é fundamenta que na educação geográfica ocorra a articulação de diferentes escalas; o local e o global devem estar conexos, integrados na construção de raciocínios espaciais complexos, aspecto essencial para o entendimento da realidade em sua totalidade. O global, visto com o conjunto articulado de processos, relações e estruturas do espaço tem um significado específico e peculiar em cada lugar; mas esse lugar não pode ser apreendido completamente se não for realizada uma articulação de seu significado com a totalidade da qual faz parte. Se o lugar carrega a referência necessária para a construção de aprendizagens significativas, a análise multiescalar é capaz de abordar os conteúdos buscando explicações, causalidades, analogias e motivações.

Com base na multiescalaridade, buscamos superar o tratamento dicotômico e excludente dos fenômenos em sua escala local ou global, como se uma dimensão não apresentasse relação com a outra. Desta forma, procuramos suplantar a conhecida abordagem dos círculos concêntricos, largamente utilizada no Ensino de Geografia nas séries iniciais do Ensino Fundamental, que expande analiticamente as escalas de estudo, partindo do local para atingir o global, do mais imediato do aluno ao mais distante ${ }^{24}$.

O questionamento à supremacia do lugar, não significa o seu abandono, mas, a construção de uma abordagem do lugar em consonância com espaços maiores; a

\footnotetext{
24" $A$ realidade dos alunos era a inspiração para todo e qualquer planejamento de atividades de ensino, proporcionando a ação destes sobre o objeto de conhecimento. A realidade fez do lugar o ponto de partida para o Ensino de Geografia, todavia, sem entender a essência do método dialético, a realidade continuava congelada em atividades descritivas, enumerativas e estáticas". STRAFORINI, Rafael. 2003, p. 584.
} 
construção de uma prática de ensino que seja capaz de relacionar o espaço vivenciado (casa, bairro, escola, com seus elementos afetivos, subjetivos e empíricos) e o espaço conhecido (da cidade, do Estado e do globo terrestre), uma abordagem que permita a percepção por parte dos jovens de que o espaço de vivência tem relação direta com os espaços distantes e longínquos. $O$ vivido carrega o paradoxo da empiria e serve de ponto de partida para outras abordagens, mas, nenhuma prática educativa pode ficar restrita a tal dimensão. Apoiando-se nesta reflexão, podemos afirmar que o lugar deve pautar o início da aprendizagem e, ao mesmo tempo, deve servir de base para o estabelecimento de abstrações mais complexas e mais amplas ${ }^{25}$. Não há como conceber o mundo linearmente, estudando a totalidade espacial em camadas. O mundo não é o somatório das partes em separado, mas tomados como indissociáveis, ou seja, as camadas só fazem sentido se encaradas em conjunto. O que é explicitado por Santos (2002) ao afirmar que 'as partes que formam a totalidade não bastam para explicá-la. Ao contrário, é a totalidade que explica as partes ${ }^{26}$.

Atualmente, é essencial que os docentes construam análises do lugar não apenas como localização de algo, ou como experiência cotidiana, familiar ou identitária, mas também, como instância que permita perceber diferenças, realizar comparações e compreender os processos que evidenciam as relações entre as diferentes escalas de análise. Ao não realizar uma abordagem multiescalar, o docente corre o risco de afastar os alunos da compreensão dos processos espaciais, reforçando o saber parcelado e fragmentado característico dos processos tradicionais de ensino. Procedimento que, em nossos dias, carrega uma tendência ao insucesso.

\section{Precisamos instrumentalizar os JOVEnS PARA A LeItURA ESPACIAL}

Nas sociedades que antecederam à escrita, o conhecimento era transmitido de geração para geração por meio da oralidade e de práticas sociais. Neste cenário, a morte de uma pessoa idosa representava a perda de um vasto leque de conhecimentos. Com o advento da escrita, o saber passou a ser registrado em livros e territorializados em bibliotecas e espaços destinados a aquisição de conhecimentos. Este último padrão predominou até recentemente. Porém, com o crescente uso das tecnologias digitais e o estabelecimento das redes de comunicação, ocorreu uma mutação da nossa relação com o saber. Em nossos dias, as informações se tornaram virtuais. De acordo com Levy (1999), o mundo digital em que vivemos, marcado pela existência do ciberespaço, das redes informacionais e pela integração virtual, produziu novas possibilidades de comunicação, alterando as relações com o saber e reduzindo a importância das estruturas territorializadas destinadas à aquisição de

\footnotetext{
25"(...) quando se evita estabelecer a conexão entre o lugar (próximo) e o global (longínquo) está fazendo um desserviço para o ensino, pois ao invés de trazer a realidade dos e aos alunos, está, na verdade, distanciando os cada vez mais" (STRAFORINI, 2002, p. 99).

${ }^{26}$ SANTOS, 2002, p. 115.
} 


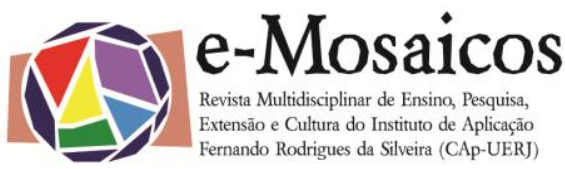

DOI: $10.12957 /$ e-mosaicos.2018.33108

conhecimentos. Assim, os processos de ensino-aprendizagem que aconteciam em espaços e tempos determinados, passaram a ocorrer, simultaneamente, em espaços e tempos não-formais, como por exemplo, nos chamados espaços virtuais.

Frente às novas relações com o saber, tornou-se fundamental que os jovens passem a ter a capacidade de ler e interpretar as diferentes formas de linguagens presentes nas estruturas informacionais. Tradicionalmente, a educação geográfica carrega uma preocupação com a linguagem (carto)gráfica. Diversos estudos procuram esclarecer os caminhos para o desenvolvimento de uma efetiva e eficiente leitura de mapas, gráficos e tabelas, um dos principais eixos norteadores do Ensino de Geografia. Todavia, é preciso ressaltar que as representações gráficas e/ou cartográficas, assim como, qualquer outra produção intelectual, científica ou não, compõe objetos culturais, estabelecidos por meio de visões de mundo, não constituindo verdades absolutas. Mapas e Gráficos manifestam construções imagéticas da realidade, expressões visuais que buscam se aproximar da realidade, porém, tais formas de representação não podem ser analisadas como um retrato fidedigno da realidade, uma vez que mapas e gráficos não abrangem a realidade em sua totalidade.

No Ensino de Geografia, adaptado aos novos tempos, é preciso garantir que os estudantes adquiram a habilidade de leitura gráfica. Mas, é igualmente importante, que os jovens adquiram a capacidade de interpretar as subjetividades e intencionalidades presentes em tais representações. Neste processo, é fundamental que o docente permita que os alunos percebam a importância de mapas, gráficos e tabelas, mas, também é basilar, garantir que eles percebam os discursos, as intencionalidades e as posições políticas presentes em suas elaborações ${ }^{27}$.

Apesar de carregar uma elevada centralidade na educação geográfica, a linguagem (carto)gráfica constitui apenas um dos instrumentos fundamentais para sua realização. Atualmente, outras formas de linguagens tornaram-se fundamentais para o sucesso das práticas escolares. Muitos docentes têm ampliado em suas práticas a utilização de diferentes fontes de informação, textos de internet, letras de músicas, trechos de livros literários, vídeos, fotografias e jogos eletrônicos constituem apenas alguns exemplos da multiplicidade de métodos empregados em nossos dias. No entanto, tais atividades precisam estar mais incorporadas ao cotidiano das aulas, trabalhadas de modo articulado ao quadro conceitual, como formas de expressão dos conteúdos, como mediação dos saberes sistematizados, e

\footnotetext{
27"O diálogo existente entre o pensar pedagógico e o saber geográfico permite afirmar que o aluno vai para a escola e aprende a ler, escrever e contar, o que se ensina com mais competência; no entanto o que menos se ensina é a ler o mundo. E é no ensinar a fazer a leitura do mundo e, portanto, no como ocorre esse processo de aprendizagem que se poderia retirar da geografia esse rótulo de matéria decorativa. Mas qual é o significado dessa leitura para os alunos do ensino básico? Saber ler uma informação do espaço vivido significa saber explorar os elementos naturais e construídos presentes na paisagem, não se atendo apenas à percepção das formas, mas sim chegando ao seu significado". CASTELAR, Sonia Maria Vanzela. 2005, p. 212.
} 
não apenas como uma ilustração do tema em tela, como costumeiramente ocorre.É preciso que as representações de fenômenos espaciais presentes em diferentes linguagens sejam entendidas em sua complexidade, 0 que inclui suas intencionalidades constitutivas. É importante considerar que todos esses recursos, inclusive imagens de satélite, representam narrativas da realidade, mas, não a realidade.

As novas abordagens exigem, em um mesmo processo de ensinoaprendizagem, a articulação entre a razão e a sensibilidade, favorecendo, simultaneamente, a construção de um conhecimento conceitual e de uma leitura estética dos processos espaciais. A cultura visual faz parte do cotidiano dos jovens, estando presente em sua percepção do mundo. Entretanto, o conjunto de imagens que percorre o nosso cotidiano, tem suas origens em processos de subjetividades hegemônicas do mundo, que contribuem, simultaneamente, para a construção da subjetividade de quem vê. Se a cultura visual que nos cerca são subjetividades e ajudam a construir subjetividades, é assim que devem ser consideradas no ensino, ou seja, devemos explicitar suas características, possibilitando com isso a construção e a desconstrução das representações espaciais.

Neste cenário, o ofício da educação geográfica tem se tornado um desafio cada vez maior, uma vez que além de dominar os conhecimentos relativos a Ciência, exige-se que os educadores saibam selecionar, utilizar e interpretar diferentes linguagens. Tornou-se fundamental que o docente tenha a capacidade de, frente a diversidade de possibilidades, investigar e escolher as mais adequadas para 0 estabelecimento de situações de ensino-aprendizagem que promovam a autonomização dos jovens. Deste modo, o instrumental analítico da leitura espacial não pode ser reduzido a um tópico do conteúdo, como ocorre, muitas vezes, com a cartografia, presente em um nível de escolaridade especifico, ou limitar os fenômenos espaciais a representações (carto)gráficas. Pelo contrário, tais noções devem fazer parte das práticas escolares de modo transversal, integrando-se a todos os temas discutidos em sala de aula. Além disso, devemos perceber que a habilidade de representação de mundos visíveis e objetivos, não se limita ao mapeamento, a localização dos objetos e a tabulação de informações, mas, igualmente, a percepção das intencionalidades presentes em cada uma delas.

\section{Precisamos ABORDAR CONTEÚdOS SOCIOESPACIAISRELEVANTES}

A riqueza de informações a qual estamos submetidos cotidianamente, associada ao hibridismo vivenciado na Geografia escolar concretizam um emaranhado de possibilidades metodológicas e uma diversidade de temas e tópicos que poderão/são objetos de abordagens no Ensino de Geografia. A existência de múltiplos caminhos a serem percorridos na aprendizagem geográfica torna imprescindível, que sejam selecionados os assuntos e os temas que serão 
fundamentais para alcançar os objetivos propostos. Neste processo, os conceitos e categorias representam os meios necessários para se atingir os objetivos propostos, mas, não podem representar o objetivo a ser alcançado. Portanto, a preocupação docente deve envolver a construção de conceitos e métodos que permitam que os alunos realizem uma reflexão sobre o espaço de maneira objetiva, tornando significativo o conhecimento geográfico abordado nas aulas ${ }^{28}$. Infelizmente, muitos docentes encaram a memorização de conceitos como um objetivo em si mesmo, como a principal meta a ser alcançada; o que os leva, continuamente, a assentar suas práticas em um conjunto de assuntos ordenados pelos currículos oficiais e/ou presentes nas estruturas temáticas existentes nos livros didáticos ${ }^{29}$. O engessamento provocado pela indiscriminada utilização de currículos prontos tem levado à realização de aulas que não carregam significância, que provocam o afastamento dos jovens do saber geográfico, muitas vezes, encarado como desnecessário e irrelevante.

Os novos tempos apontam que as práticas da educação geográfica assentadas em conteúdos distantes da realidade dos alunos devem ser abandonadas e, em seu lugar, estabelecidas aulas que carreguem significância para os estudantes. A construção de processos de aprendizagem significativos decorre da relação que estabelecemos entre as novas ideias, informações e conceitos e o conjunto de saberes disponíveis e previamente adquiridos pelos indivíduos. Em outras palavras, devemos procurar construir uma Geografia escolar apoiada em uma aprendizagem significativa, que carregue um sentido de relevância para os indivíduos, que possa ser conectada a conhecimentos previamente adquiridos e que possa ser compartilhada. Desta forma, as práticas escolares não podem ser direcionadas, exclusivamente, por manuais, normas curriculares e livros didáticos.

A definição dos currículos oficiais é, essencialmente, o espelho das relações de poder existentes na sociedade. Na construção dos currículos oficiais, algumas vozes

\footnotetext{
28 "Trabalhar a partir da construção de conceitos implica em profundas transformações não só no desenvolvimento da disciplina em sala de aula, mas também no ato de planejar o seu desenvolvimento. A construção de conceitos passa a ser um fim, ao passo que os conteúdos transformam-se em meios, o que contribui de forma substancial para criar uma Geografia menos informativa e portanto mais formativa, comprometida com a construção do cidadão consciente" (SOUZA, 2001, p. 9).

29 "pensar a geografia como uma disciplina que ensina a memorizar informações soltas é uma ideia equivocada. Por isso construir a ideia de espaço na sua dimensão cultural, econômica, ambiental e social é um grande desafio da geografia, e da geografia escolar. Mais, ainda, pensar que os fenômenos geográficos podem ser analisados articuladamente e em diferentes escalas, o que significa analisá-los conceitualmente, em função de diversas práticas e das representações sociais.(...) Todas as tentativas são em direção a renovações que implicam mudanças na postura, na linguagem e nas atividades de aprendizagem necessárias para que o aluno reflita sobre a realidade, a sociedade e a dinâmica do espaço. No entanto o discurso praticado nos séculos XIX e XX continua a ser reproduzido até hoje. Por isso a geografia escolar ainda aparece no currículo como sendo aquela área de conhecimento de menor aplicação prática fora da escola, mesmo que essa situação receba críticas desde meados de 1980" (CASTELAR, 2005, pp. 211-212).
} 
têm mais força e expressão, enquanto outras são silenciadas ou mesmo distorcidas. A construção destes documentos não carrega uma neutralidade, pelo contrário, demonstram as contradições existentes nas sociedades. Assim, determinados grupos sociais não estão representados nestes documentos, seus conceitos, sua cultura e suas relações socioespaciais estão alijadas do saber escolar e, consequentemente, ausentes das salas de aula. Portanto, ao contrário de procurarmos cumprir a totalidade dos manuais, devemos estabelecer os paralelos espaciais entre o saber a ser ensinado e o saber vivenciado pelos alunos, construindo as conexões conceituais e procedimentais possíveis, para, posteriormente, elaborarmos os itinerários pedagógicos que serão propostos.

O Ensino de Geografia adaptado aos novos tempos torna imperativo que os documentos oficiais e as estruturas temáticas, presentes nos livros didáticos e manuais escolares, sejam reconsiderados e recontextualizados. A transposição didática, ou seja, a transformação do saber acadêmico em um saber a ser ensinado, não pode ser automática, ela deve ser estabelecida com base nos diferentes contextos existente nas escolas e vivenciados pelos estudantes em suas práticas sociais $^{30}$. A transposição didática, independentemente de nossas opções políticas ou de nossas referências acadêmicas, deve se pautar pela apresentação de contextos socioespaciais próximos a realidade da escola e dos alunos. 0 educador deve se apresentar como um mediador, o que implica em realizar uma profunda reflexão sobre a contribuição que a Geografia e, consequentemente, seu conjunto de conceitos e categorias de análise, pode produzir na vida cotidiana dos jovens ${ }^{31}$. Cabe ao docente ser o condutor do ensino, mas, cabe ao jovem, sujeito do processo de aprendizagem, a escolha do caminho que será trilhado.

Atualmente, a escola não constitui mais um espaço fechado e descolado do seu entorno, pelo contrário, cada vez mais o espaço escolar sofre influência das relações estabelecidas pelos agentes sociais que, direta ou indiretamente, se relacionam com seus processos formativos. Hoje, a escola deve ser pensada como uma expressão das relações e das formas de socialização existentes, um espaço que se encontra permanentemente integrado com a rua, com os equipamentos públicos

\footnotetext{
${ }^{30}$ A transposição didática é entendida como um processo, no qual "um conteúdo do saber que foi designado como saber a ensinar sofre a partir daí, um conjunto de transformações adaptativas que vão torna-lo apto para ocupar um lugar entre os objetos de ensino. O trabalho que transforma um objeto do saber a ensinar em um objeto de ensino é denominado Transposição Didática" (CHEVALLARD, 1991, p. 45).

31 "A geografia escolar (será que existe mais de uma geografia?), mais do que nunca, deve ser trabalhada de forma a instrumentalizar os alunos para lidarem com a espacialidade e com suas múltiplas aproximações: eles devem saber operar o espaço! Tal postura procura dar conta da compreensão da vida social refletida sobre os diferentes sujeitos, agentes responsáveis pelas (trans)formações. Com isso, parece ficar mais fácil para o sujeito reconhecer as contradições e os conflitos sociais e avaliar constantemente as formas de apropriação e de organização estabelecidas pelos grupos sociais e, quando desejar, buscar mecanismos de intervenção" (CASTROGIOVANNI, 2007, p. 43).
} 
de lazer, de compras, com os espaços religiosos, com as redes virtuais e com as diversas expressões culturais existentes. Desta forma, as múltiplas experiências vivenciadas fora dos muros escolares não devem ser desprezadas pela educação geográfica. Pelo contrário, elas devem ser valorizadas e evidenciadas, pois não há como impor unilateralmente uma ordem à realidade vivida, uma vez que os alunos expressam no ambiente escolar as múltiplas facetas do vivido. Os itinerários pedagógicos propostos pela Geografia devem ser pensados com base nas questões presentes na comunidade escolar. Não é a 'sala de aula' e a realidade dos estudantes que devem se adequar aos currículos oficiais, pelo contrário, os currículos escolares devem ser adequados a realidade vivenciada pelos jovens. É refletindo sobre aspectos reais e próximos que o raciocínio geográfico se torna fundamental, rico e significativo. Portanto, devemos fugir da homogeneidade dos currículos prontos e procurar as singularidades que uma educação geográfica pautada em tópicos e temas relevantes pode produzir.

\section{CONSIDERAÇões FinAIS}

A leitura do mundo precede a leitura da palavra, daí que a posterior leitura desta não pode prescindir da continuidade da leitura daquele (a palavra que eu digo sai do mundo que estou lendo, mas a palavra que sai do mundo que eu estou lendo vai além dele).(...) se for capaz de escrever minha palavra estarei, de certa forma transformando o mundo. $O$ ato de ler o mundo implica uma leitura dentro e fora de mim. Implica na relação que eu tenho com esse mundo (FREIRE, 1997, p. 13).

A crise vivenciada pelas escolas tem sua origem ligada a transição entre dois modelos de sociedade. Neste processo, novas subjetividades emergem, assim como, novas competências passam a ser exigidas dos estudantes. Porém, as estruturas escolares, seus procedimentos e normas ainda não se adequaram aos novos tempos, precisando ser revistas e modificadas. Muitas escolas continuam encarando os estudantes como indivíduos que não carregam desejos, sonhos e vontades; indivíduos que devem se submeter a uma disciplina que não encontra mais respaldo social.

O espaço escolar, ainda muito marcado pelos procedimentos inerentes a Sociedade Disciplinar, impõe um trabalho em ritmo acelerado, fragmentado, sem reflexão e sem integração entre os docentes, o que dificulta a experiência da inovação e favorece a existência de práticas insipidas, sem sentido real e descoladas do mundo vivido. Em razão das inúmeras dificuldades enfrentadas, alguns professores, se sentem inseguros e se fecham em atitudes conservadoras, optando por manter os rituais rotineiros e repetitivos da sala de aula, desistindo de 
experimentar caminhos novos e reproduzindo práticas que não promovem uma educação voltada para a autonomização dos alunos. Encaram a sala de aula como uma estufa, em que a função dos estudantes é simplesmente engolir um conjunto de noções e depois cuspi-las em avaliações sem sentido.

Em um extremo oposto, muitos professores têm sido inovadores, variando métodos, procedimentos e linguagens, desenvolvendo aulas em espaços não convencionais, utilizando diferentes recursos, procurando adaptar esses aspectos a realidade dos alunos, ao contexto das escolas. As inovações se manifestam também na prática de avaliações mais qualitativas e formativas e na busca de um relacionamento mais negociado e dialógico com os jovens. É cada vez maior o número de docentes que pautam seu trabalho pelo desejo permanente de promover uma aprendizagem significativa, envolvendo seus alunos em projetos profissionais a projetos sociais mais amplos. Tais professores não buscam a simples utilização de recursos técnicos, comumente, apontada como a receita para um ensino inovador, eles sabem que isso não basta, por isso se abrem ao novo e a novas práticas.

A solução para a crise passaria pela construção de um novo modelo de Educação. No novo modelo as escolas não devem continuar sendo encaradas como locais exclusivos da aprendizagem, mas, apenas como pontos de partida da construção destes processos. Atualmente, por exemplo, as cidades, grandes ou pequenas, carregam um potencial educativo pouco utilizado. Estes espaços dispõem de inúmeros locais com potencial formativo, bibliotecas, praças, ruas, parques, clubes, organizações sociais entre outros, no entanto, os mesmos são pouco acessados e permanecem descolados dos processos de aprendizagem. Processo semelhante ocorre com as novas tecnologias, sobretudo, em relação as redes informacionais que conectam instituições e indivíduos geograficamente distantes, no entanto, intelectualmente e pedagogicamente próximos. Existe uma potência formativa pouco explorada e aproveitada nas escolas; uma potência que seria capaz de contribuir para a construção de processos formativos que sejam capazes de expressar a riqueza da existência humana e ampliar nossa capacidade de convívio com as diferenças.

O caminho é longo, estamos apenas no início do percurso, porém, estamos caminhando de forma contínua. O Ensino de Geografia no século XXI deve ensinar o aluno a descobrir, a trilhar seu próprio caminho, não apenas reproduzir em um outro nível o conteúdo acadêmico, pelo contrário, tais conteúdos devem ser reatualizados, reelaborados em função da realidade do aluno e do seu meio. Devemos abandonar o tripé metodológico da Geografia tradicional - localizar, descrever e analisar precisamos atingir um cenário pedagógico em que a compreensão, a comparação, a sistematização e a relação se tornem marcas do fazer geográfico em sala de aula. Devemos ensinar a aprender e a Geografia deve, fundamentalmente, ensinar a viver! 
DOI: $10.12957 /$ e-mosaicos.2018.33108

\section{REFERÊNCIAS}

APPLE, M. W. Educação e Poder. Porto Alegre: ARTMED, 2002.

ARROYO, M. G. Currículo, território em disputa. Petrópolis, RJ: Vozes, 2011.

ARROYO, M. Políticas Educacionais e Desigualdades: à procura de novos significados. In: Educação e Sociedade. Campinas. Unicamp, v. 31, n. 113, outubro-dezembro. 2010. pp 1381-1416.

AUSUBEL, D. Psicologia Educacional. Rio de Janeiro: Editora Interamericans, 1980.

CANÁRIO, R. A escola: das promessas as incertezas. In: Revista Educação Unisinos. Porto Alegre, $\mathrm{n}^{\circ}$ 12, maio-agosto. 2008. pp 73-81.

CAPEL, H; URTEAGA, L. Las Nuevas Geografias. Barcelona: Salvat Editores. 1983.

CARLOS, A. O lugar no/do mundo. São Paulo: Labur Edições, 2007.

CASTELAR, S. Educação Geográfica: a Psicogenética e o conhecimento escolar. In: Caderno Cedes, Campinas, vol. 25, n. 66, p. 209-225, maio/ago. 2005

CASTROGIOVANNI, A, CALLAI, H, KAERCHER, N. Geografia: prática pedagógicas para o ensino médio. Porto Alegre Artmed, 2007.

CAVALCANTI, L. Geografia e educação no cenário do pensamento complexo e interdisciplinar. In: Boletim Goiano de Geografia. $n^{0}$ 22(2), 2002. pp. 123-136.

CAVALCANTI, L. Geografia e práticas de ensino. Goiânia: Alternativa, 2002.

CLAVAL, P. Terra dos Homens: A Geografia. São Paulo: Editora Contexto, 2010.

CHEVALLARD, Y. La Transposition Didactique: Du SavoirSavantauSavoirEnsigné. Grenoble, La pensée Sauvage. 1991.

DELEUZE, G. Conversações - 1972-1990. São Paulo: Editora 34, 1992. 232p.

FOUCAULT, M. Segurança, Território e População. Curso no Collège de France (19771978). São Paulo: Martins Fontes, 2008.

Vigiar e Punir. história da violência nas prisões. Petrópolis: Vozes, 1987.

FREIRE, P. A importância do ato de ler. em três artigos que se completam. 34a edição. São Paulo: Cortez, 1997. 
DOI: $10.12957 /$ e-mosaicos.2018.33108

LÉVY, P. Cibercultura. São Paulo: Editora 34, 1999.

LIPOVETSKY, G. A estetização do mundo: viver na era do capitalismo artista. São Paulo: Companhia das Letras, 2015.

MORAES, A. O Sentido Formativo da Geografia. In: Revista de Estudos Avançados da USP. 2013. 12p. disponível na internet http://www.iea.usp.br/publicacoes/textos/sentidoformativogeografia.pdf

MOREIRA, M. Aprendizagem significativa: a teoria de David Ausubel. São Paulo: Editora Moraes, 1982. $112 \mathrm{p}$.

PIAGET, J. $A$ equilibração das estruturas cognitivas - problema central do desenvolvimento. Rio de Janeiro: Zahar Editores, 1976.

SANTOS, M. Geografia: além do professor? In: Revista Geographia. Niterói - Rio de Janeiro, v.13, n.25, p.7-15, 2011.

- Repensando o Espaço do Homem. 5a Edição. São Paulo: Editora da Universidade de São Paulo, 2007.

· A Natureza do Espaço: técnica e tempo, razão e emoção. São Paulo: Editora da Universidade de São Paulo, 2002.

SIBILIA, P. Redes ou paredes: a escola em tempos de dispersão. Rio de Janeiro: Contraponto, 2012.

STRAFORINI, R. A Totalidade mundo nas primeiras séries do Ensino Fundamental: Um desafio a ser enfrentado. In: Revista Terra Livre. São Paulo, Ano 18, Vol.1, n ${ }^{0} 18$. 2002, pp. 95-114.

SUERTEGARAY, D. Geografia e interdisciplinaridade. Espaço geográfico: interface natureza e sociedade. In: Revista Geosul, Florianópolis, v.18, n.35, jan./jun. 2003. pp. 43-53.

VESENTINI, W. Repensando a geografia escolar para o século XXI. São Paulo: Plêiade, 2009. 